\title{
El agua de riego en la construcción del paisaje cultural en las zonas áridas del centro-oeste argentino. Un caso de estudio: Chañarmuyo, La Rioja ${ }^{1}$
}

\author{
Guillermo Rolón² y Rodolfo Rotondaro²
}

\begin{abstract}
RESUMEN
La ocupación del territorio resulta de un complejo proceso donde el hombre transforma y adecua su entorno natural para habitarlo. En las regiones áridas, uno de los factores más importantes en este proceso es la obtención y administración del agua. Se presenta un análisis focalizado en las modificaciones de la ocupación del territorio en el pueblo rural de Chañarmuyo desde el punto de vista de las sucesivas mejoras de los sistemas de captación y distribución de agua. Se indaga sobre los principales grupos humanos e institucionales vinculados a los modos de gestión del manejo del recurso hídrico, y se caracterizan las transformaciones de su paisaje cultural. De este modo se pretende brindar un panorama de la problemática hídrica y su relación con la construcción de la espacialidad rural que ocurren en esta región particular del noreste riojano.
\end{abstract}

Palabras clave: Recurso hídrico, paisaje vernáculo, regiones áridas, Chañarmuyo.

\begin{abstract}
Territory occupation is a complex process where human transforms and adapts their natural environment in order to inhabit it. In arid regions, one of the most important factors during this process is the obtaining and management of water. In this paper an analysis, focused in the modification of land occupation in the rural area of Chañarmuyo, viewed from the successive improvements in collection system and water distribution, is presented. An investigation of main human and institutional groups related to management models and administration of water resource is made, as well as a characterization of its cultural landscape transformation. The aim of this study is to provide an overview of the water problem and its relationship with rural spatiality construction in this particular region of La Rioja.
\end{abstract}

Key words: Water resources, vernacular landscape, arid regions, Chañarmuyo.

1 Artículo recibido el 12 de marzo de 2010, aceptado el 19 de mayo de 2010 y corregido el 15 de junio de 2010.

\footnotetext{
2 Instituto de Arte Americano e Investigaciones Estéticas "Mario J. Buschiazzo", Universidad de Buenos Aires. E-mail: grolon@fadu.uba.ar; rotondarq@telecentro.com.ar
} 
La permanente interacción entre el hombre y la naturaleza construye paisajes culturales o vernáculos que constituyen la evidencia presente y pasada de esta relación entre una sociedad y su entorno natural (Calvo-Iglesias et al., 2006; UNESCO, 2006; Eben Saleh, 2001). El agua, en las zonas áridas, es el componente más importante y crítico de esta interacción entre la actividad humana y el medio ambiente natural; incide directamente sobre las condiciones biológicas, físicas, culturales, estéticas y políticas del hábitat (Burmil et al., 1999). Este recurso regula las posibilidades de existencia y crecimiento de la población, por lo que el bienestar del hombre y su comunidad dependen de su adecuado y constante suministro (Potter \& Darmame, 2010).

En América Latina y el Caribe el $26 \%$ del territorio está constituido por tierras secas, mientras que en Argentina las tres cuartas partes de su extensión territorial son zonas áridas y semiáridas. En estas regiones del territorio argentino los sistemas de riego son fundamentales para la existencia y progreso de gran parte de sus poblados. Estos asentamientos humanos se constituyen así en oasis de riego que albergan al 30\% de la población del país en áreas de limitada extensión; un caso representativo es la provincia de Mendoza, donde apenas ocupan entre el 2,5\% y el $4 \%$ de la superficie provincial (Abraham, 2002). Es de notar, además, que el perfeccionamiento y la innovación de los sistemas de riego y la mejora en los modos de gestión, en estas regiones, han posibilitado el surgimiento de importantes actividades agrícolas en los últimos años; por ejemplo, en el manejo del recurso hídrico se ha comenzado a tener en cuenta la importancia no solo de los caudales permanentes, sino también la complementación con los caudales temporales, la reutilización de aguas de riego y la explotación de fuentes subterráneas (Torres et al., 2008; Torres et al., 2003).

Las tecnologías de captación y distribución del recurso hídrico y sus modos de gestión son numerosos y han sido estudiados por diversos autores (León y Váldes, 2008; Salomón et al., 2008; Torres Guevara, 2006; Torres Guevara y Claros Maquera, 2005). Estas tecnologías no solo regulan la disponibilidad del recurso hídrico, también inciden di- rectamente sobre la posibilidad de expansión y distribución de nuevas tierras productivas, constituyéndose de este modo en principales agentes de ordenación del territorio y transformadores del paisaje cultural. Según Nüsser (2001), en las regiones marginales para el hábitat humano, el análisis de las transformaciones del paisaje cultural requiere tener en cuenta las potencialidades, las limitaciones y los riesgos de la utilización de los recursos naturales junto con los aspectos socioeconómicos e históricos de los sistemas de uso de la tierra.

El concepto de paisaje cultural (paisaje en sentido antropológico) es semejante al de espacialidad que Soja (1985) define como parte de un producto de la sociedad y estructurante de la vida social que involucra el tiempo y el espacio, en permanente conflicto, reformulación y reproducción. Ingold (1993) considera, además, que "...the landscape is constituted as an enduring record of -and testimony tothe lives and works of past generations who have dwelt whiting is, and in so doing, have left there something of themselves" (Ingold, 1993: 189).

En las zonas áridas, la disponibilidad de agua, su gestión y las formas de apropiación de la tierra son componentes que inciden con mayor determinación en este proceso de construcción del paisaje cultural. Natenzon (1989) plantea un modelo general de ocupación territorial de los asentamientos en regiones áridas cuando sostiene que "... una sociedad se apropia del agua en un primer momento superponiéndose a su distribución geográfica y allí donde esta se localice, sin mediaciones instrumentales ni modificaciones sustanciales; luego, modificándola en función de sus intereses, industrias y posibilidades técnicas; finalmente, Ilevándola (transportándola) allí donde el agua fuera requerida. Pero esta apropiación/modificación/ intervención será realizada en función de intereses parcelados, emergentes de aquel sector de la sociedad que logre imponerse a los intereses de los restantes sectores sociales..." (Natenzon, 1989: 4). 


\section{El contexto rural en el análisis del paisaje cultural}

El asentamiento actual de Chañarmuyo, como paisaje cultural, combina un aglomerado organizado linealmente y vivienda dispersa con productividad agraria. Predomina la escala doméstica y la organización de actividades y tiempos cotidianos característicos de un territorio que se puede considerar netamente rural dentro de Argentina, aunque con un incremento reciente de los intercambios comerciales y turísticos con la zona y la región.

En este sentido, el abordaje de la problemática del agua en Chañarmuyo debe tener en cuenta el concepto de hábitat rural. Castro y Reboratti (2007), por ejemplo, cuando analizan las dificultades en la definición de ruralidad, en relación a la clásica dicotomía urbano-rural, aclaran que “... es mucho más adecuado pensar en una distribución de la población en un continuum rural/urbano, que vaya de situaciones donde la población está preponderantemente dispersa hasta las grandes aglomeraciones urbanas..." (Castro y Reboratti, 2007: 52) El caso en estudio se ajusta más a esta noción de un territorio antropizado funcionando en red con los otros asentamientos de la zona (en particular con los pueblos vecinos de Campanas y Pituil), que a una visión de pueblo rural aislado solamente unido por caminos con otros pueblos y ciudades.

Una investigación realizada por la Facultad de Agronomía de la Universidad de Buenos Aires (1996) considera que “... la noción de hábitat rural [...] designa el ámbito de confluencia y/o interacción entre el solar residencial de las unidades domésticas rurales y el suelo agrario dedicado a producciones para el consumo de unidades domésticas y/o para su destino al mercado" (Facultad de Agronomía de la Universidad de Buenos Aires, 1996: 11).

También, en referencia a la vivienda en los contextos rurales, la opinión de algunos autores parece estar acorde con la realidad del Chañarmuyo actual. Tena Núñez (1999), en su conceptualización sobre las relaciones de la vivienda con su entorno, sostiene que "la ocupación del territorio y su consecuente apropiación como pueblo, tiene un carácter comunitario y es un soporte para la identidad cultural, ya que constituye un habitus (Bourdieu) particular y único, donde la vivienda cumple un papel fundamental como sitio de autoreferencia e integración, que permite la dualidad pueblo-lugar y pueblo-gente; así, la vivienda sembrada en el territorio es una forma primaria que materializa la apropiación del espacio y del entorno, con la cual se sientan las bases de la reproducción cultural y el desarrollo social del pueblo (individuos, familias, comunidad, grupos y subgrupos)" (Tena Núñez, 1999: 138).

Chañarmuyo, aun con los cambios en las formas productivas y las migraciones que ocurrieron en las últimas décadas, tiene condiciones de vida y una dinámica eminentemente rurales, de pueblo rural, claramente estructurado por la interacción con su entorno natural a partir de sus actividades productivas agrarias y cría de animales a escala doméstica. En la observación de la arquitectura de las viviendas y de los usos en sus entornos productivos, por ejemplo, hay rasgos morfológico-espaciales que evidencian esta interacción (tales como los piletones y pequeñas bodegas familiares, los aterrazados de cultivos, las huertas y los corrales para animales de granja) y que también refieren a la dimensión de la vivienda como un proceso ligado al grupo humano y su forma de vida económica.

En este sentido, González Claverán (1999) sostiene que "la vivienda rural, al igual que la vivienda urbana, se puede definir como un objeto pero que también es un proceso, sobre todo en el medio rural en que esta más que una mercancía objeto de compra-venta se convierte en una práctica individual, familiar o comunal o incluso, muchas de las veces en un ritual" (González Claverán, 1999: 57).

\section{Marco de la investigación}

Esta investigación intenta comprender cómo la disponibilidad y el uso del recurso hídrico destinado al riego, desde sus primeras características prehispánicas hasta sus rasgos actuales, produjeron modificaciones del paisaje cultural de Chañarmuyo. Para ello se tie- 
ne en cuenta el concepto de paisaje cultural definido por la UNESCO como la "...variedad de manifestaciones de la interacción entre la humanidad y su entorno natural" (UNESCO, 2006: 132) que "ilustran la evolución de la sociedad y de los asentamientos humanos a lo largo de los años, bajo la influencia de las limitaciones y/o de las ventajas que presenta el entorno natural y de fuerzas sociales, económicas y culturales sucesivas, internas y externas" (UNESCO, 2006: 132). Para explicar las transformaciones del paisaje cultural del área en el período reciente, generados por los cambios en el sistema de riego, los objetivos de la investigación se orientan a: a) analizar las modificaciones en la organización del territorio y en la estructura agraria vinculadas a las mejoras de los sistemas de captación y distribución de agua; y b) describir los principales grupos humanos e institucionales asociados a los modos de gestión del manejo del recurso hídrico.

\section{Materiales y métodos}

La metodología empleada se basa en un estudio de caso de uno de los pueblos rurales, Chañarmuyo, como ejemplo de la problemática del uso del agua en pequeñas poblaciones rurales dentro del departamento de Famatina, en el noreste de la provincia de La Rioja, en el centro-oeste de Argentina.

Se partió de la selección y análisis del material recopilado durante varios trabajos de campo realizados entre 2004 y 2010. En ellos se estableció contacto con sus habitantes y se realizaron entrevistas informales, recopilando información mediante fichas de registro sobre los cambios producidos a raíz de la implementación de nuevos sistemas de irrigación y de la formas de organización de los regantes que ellos observaban. A través de relevamientos gráficos y fotográficos se realizó un registro de las zonas de interés para la investigación: dique, acequias, campos de cultivo, cuenca del río, viviendas y diversos tipos de construcciones.

Para profundizar aspectos referentes a las obras de captación, almacenamiento y distribución del agua, los modos de gestión, la cantidad de explotaciones agropecuarias, el número de productores y el tipo de produc- ción, se realizó una búsqueda bibliográfica y entrevistas con funcionarios de instituciones provinciales pertinentes tales como la Secretaría del Agua, la Secretaría de Agricultura y Recursos Naturales, la Agencia de Extensión Rural Chilecito (AER INTA Chilecito) del Instituto Nacional de Tecnología Agropecuaria (INTA), la Entidad de Enlace del Programa de Servicios Agrícolas Provinciales La Rioja (EE PROSAP La Rioja), la Dirección General de Catastro y el Archivo Histórico Provincial (AHP-LR), con el objetivo de recolectar información que pudiese favorecer el análisis. Para abordar las características generales de la población y vivienda correspondiente al departamento de Famatina y al pueblo de Chañarmuyo, se consultó información estadística de 2001 y de 2008 elaboradas por el Instituto Nacional de Estadísticas y Censo $(\text { INDEC, 2002) })^{3}$ y por la Dirección General de Estadísticas y Sistemas de Información ${ }^{4}$ de la provincia de La Rioja respectivamente. La información estadística del sector productivo agropecuario se extrajo del Censo Nacional Agropecuario de 2002 (CNA-INDEC).

Para recopilar información sobre las transformaciones del aspecto físico y de la ocupación territorial se trabajó sobre una fotografía aérea de 1964 en escala 1:40.000 (Figura $N^{\circ} 1$ ), aportada por la Secretaría de Minería del Servicio Geológico Minero Argentino (SEGEMAR), y una imagen satelital de Google Earth a escala semejante (Figura $N^{\circ} 2$ ).

\section{Componentes del paisaje cultural}

\section{Caso de estudio}

El pueblo de Chañarmuyo (28 $38^{\circ}$ latitud Sur, $67^{\circ} 34^{\prime}$ longitud Oeste) se ubica en el departamento de Famatina, en el noreste de la provincia de La Rioja (Figura $N^{\circ} 3$ ) y cuenta con una población de 253 habitantes y 89 viviendas (INDEC, 2001). En el período colonial, este territorio formó parte de una merced de tierras (De la Vega Díaz, 1994)

\footnotetext{
3 Censo Nacional de Población, Hogares y Viviendas de 2001.

4 Censo de Población, Hogares y Viviendas, La Rioja 2008. Datos preliminares, junio de 2009.
} 
EL AGUA DE RIEGO EN LA CONSTRUCCIÓN DEL PAISAJE CULTURAL EN LAS ZONAS ÁRIDAS

Figura $\mathrm{N}^{\circ} 1$

Fotografía aérea de Chañarmuyo

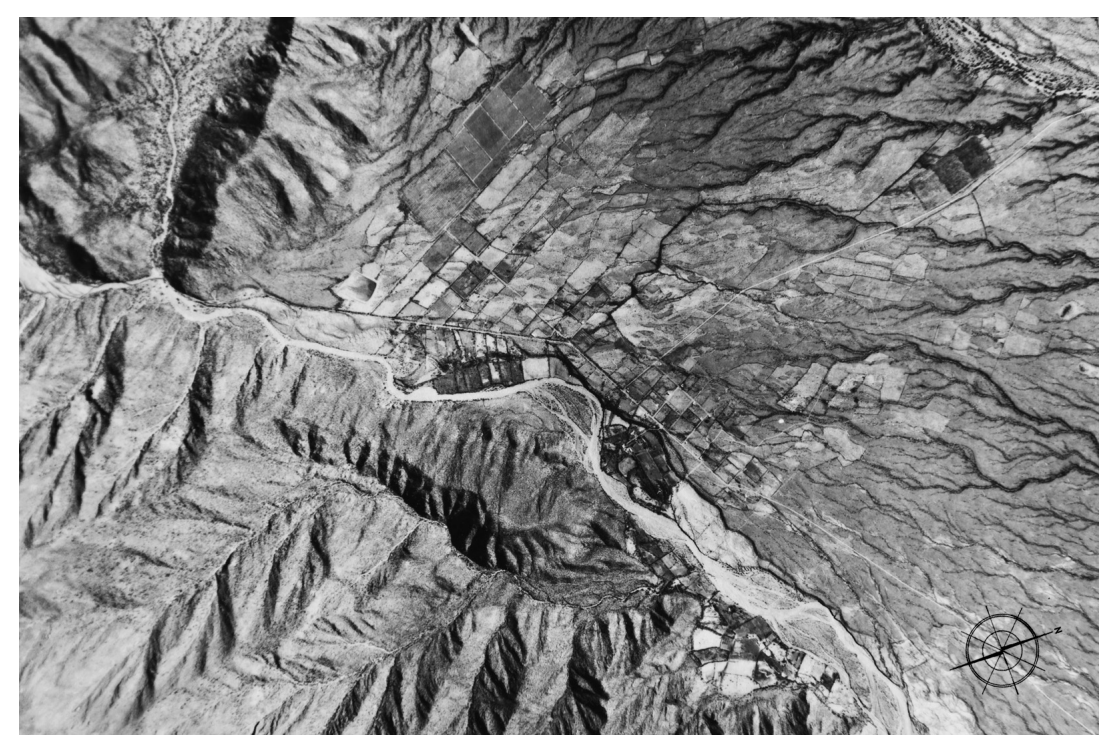

Fuente: SEGEMAR, 1964, escala original de la imagen 1:40.000.

Figura $\mathrm{N}^{\circ} 2$

Fotografía satelital de Chañarmuyo

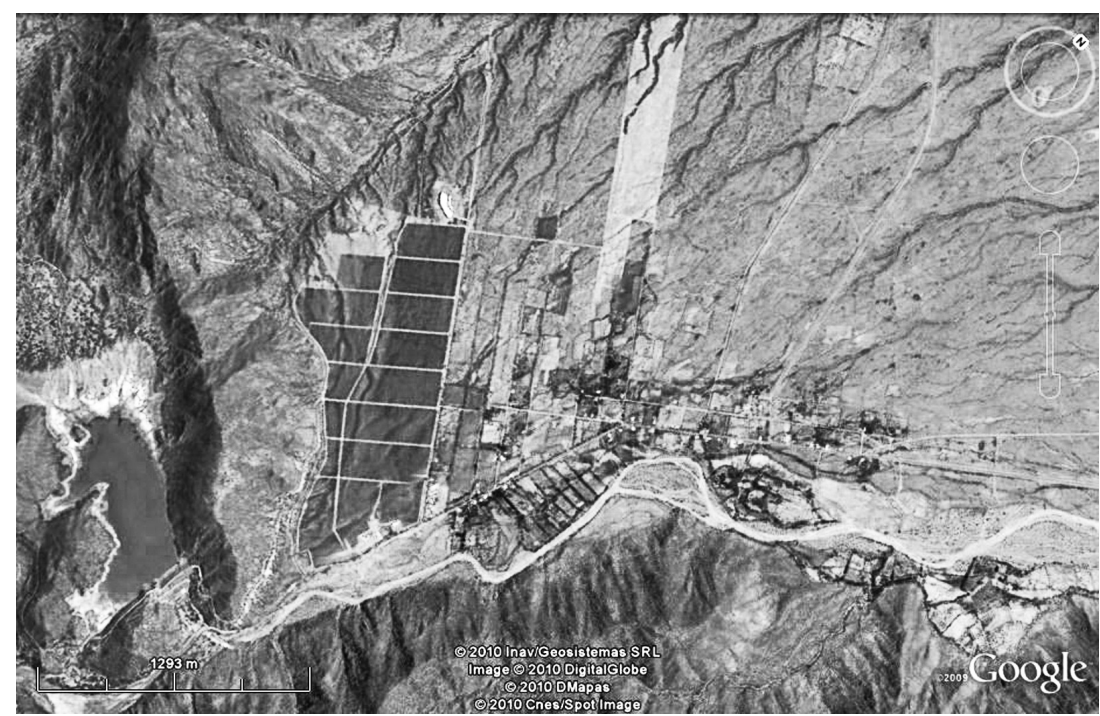

Fuente: Google Earth, octubre de 2004. 
previamente habitado por comunidades de pobladores originarios (Callegari et al., 2010). El poblado se encuentra ubicado en el sector septentrional de las sierras del Paimán, al inicio de la quebrada por donde circula el río homónimo. En la parte habitada, la topografía alcanza alturas desde 1.600 a 1.700 m.s.n.m., mientras que los cerros circundantes rondan entre los 2.000 y 2.200 m.s.n.m. El clima es de tipo continental, templado cálido con condiciones semiáridas, característico del noroeste argentino. Predomina el monte arbustivo con abundancia de vegetación xerófila donde se encuentran principalmente jarillas (Larrea spp.), retamos (Bulnesia retama), pichanas (Cassia aphyla), breas (Cercidium praecox) y algarrobos (Prosopis spp.). Por su parte, la actividad humana introdujo distintas variedades de árboles y arbustos frutales de valor económico. También se plantaron álamos (Populus nigra), en su mayoría para protección contra la acción del viento y para demarcar los límites de los terrenos de cultivo; algarrobos; sauces (Salix humboldtiana); pimientos (Schinus molle), para adecuar los espacios de hábitat aprovechando su sombra; o los característicos membrillos (Cydonia oblonga), empleados generalmente en cercos de cultivos y de predios (Figura $\mathrm{N}^{\circ} 4$ ).
Figura $\mathrm{N}^{\circ} 3$

Ubicación de Chañarmuyo

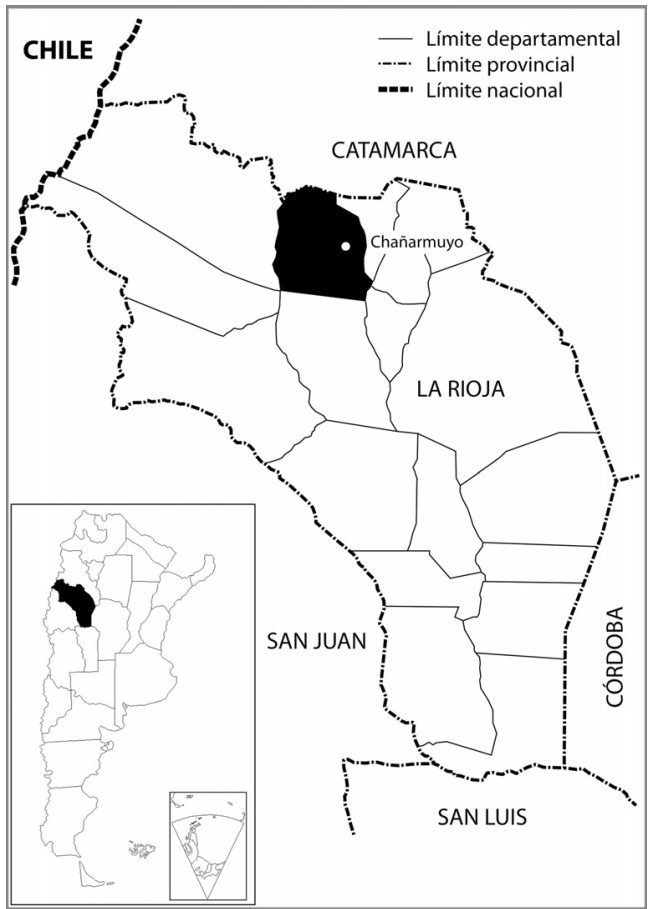

Fuente: Elaboración propia.

Figura $N^{\circ} 4$

Vista parcial de Chañarmuyo; en primer plano la finca de mayor extensión con cultivos

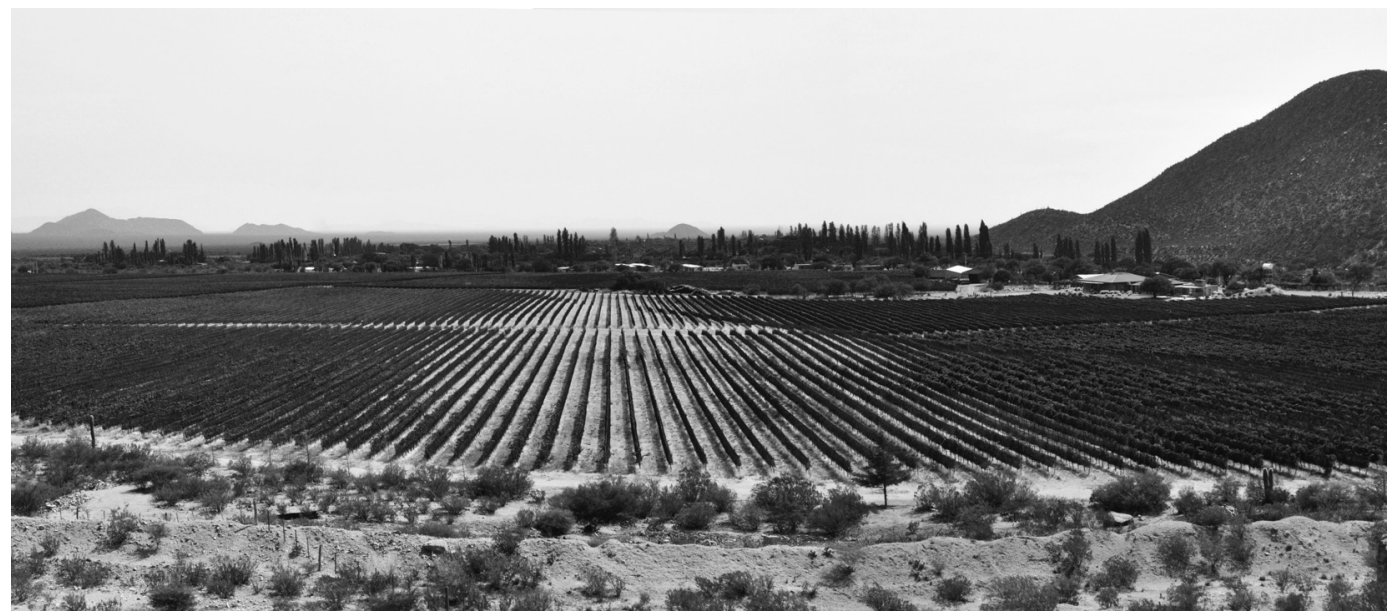

Fuente: Colección personal de los autores. 
En general, el uso de la tierra en Chañarmuyo puede ser caracterizada como una economía agropastoril con moderada integración al sistema mercantil. Se destacan los cultivos por irrigación y la cría de animales de granja. La irrigación depende casi por completo de la reserva de agua contenida en el dique, debido a que los únicos períodos de Iluvias transcurren entre septiembre y febrero, con un promedio de precipitaciones que no superan los 200 mm/año. Según información aportada por la AER INTA Chilecito y la Secretaría de Agricultura y Recursos Naturales, los principales cultivos corresponden a la vid; de las 158 ha plantadas en este distrito, 110 ha pertenecen a la finca de mayor extensión. En el resto de las fincas presentan cultivos de olivo, nogal, durazno, manzanas, peras, tomate, cereales y forrajeras que componen las principales plantaciones; además, se pudo observar que en general predomina el empleo de baja tecnología y poca eficiencia en las tareas agrícolas. Debido a la diversidad de cultivos para consumo propio, la demanda de tareas agrícolas se prolonga durante gran parte del año.

\section{Antecedentes de ocupación prehispánica}

Al este del pueblo de Chañarmuyo, distante a $4 \mathrm{~km}$, se encuentra un importante asentamiento prehispánico, que ocupa algo más de 150 ha, denominado La Cuestecilla. Este sitio se dispone sobre el inicio de un extenso barreal en el margen sur del río Chañarmuyo y está bordeado por la ruta provincial $N^{\circ}$ 39. Callegari et al. (2000) comentan que el sitio presenta diferentes tipos de estructuras espaciales, jerarquizadas, que cuentan con una organización aparentemente centralizada y rodeadas periféricamente por numerosos campos de cultivos. La mayoría de estos campos se ubican próximos al río, organizados en hileras paralelas de tierra y de manera perpendicular a la pendiente del terreno. Están delimitados entre sí por montículos de tierra y piedra de escasa altura. Según mediciones radiocarbónicas realizadas, el asentamiento presentó un amplio período de ocupación en el tiempo entre el 100 a. C. al 1300 d. C. (CaIlegari et al., 2010). Los autores desconocen hasta el momento si posteriormente aconteció un proceso de abandono del asentamiento por parte de las poblaciones originarias $\mathrm{O}$, si con el tiempo, hubo un cambio en la ideo- logía religiosa dominante, provocando una innovación en la estructura y organización social $^{5}$.

\section{La ocupación reciente: los pueblos de Chañarmuyo}

En el área de estudio se identifican dos zonas de localización distintas: un sector conocido por los pobladores como La Banda y otro como El Pueblo Nuevo (Figura $N^{\circ} 5$ ). El primer sector se ubica hacia el este, entre el piedemonte y ambas márgenes del río. Los pobladores lo reconocen como el primer asentamiento de Chañarmuyo ${ }^{6}$. En documentos oficiales (Provincia de la Rioja, 1870-1871) esta parte de merced de tierras ya aparece mencionada como poblado para la segunda mitad del siglo XIX. Es un área con campos de cultivos activos donde se mantienen en pie las construcciones de vivienda y de equipamiento doméstico y productivo de mayor antigüedad. La organización de los cultivos, de formas y dimensiones variables, es carente de regularidad geométrica y aparecen alineados con las formas serpenteantes del curso del río y de la ladera de los cerros. Las viviendas y construcciones auxiliares, la mayor parte en estado de abandono, tienden a ocupar sectores centrales y/o elevados dentro de cada propiedad. Actualmente, La Banda solo es habitada de manera permanente por una familia, la de Zulma Castro. Gran parte de este sector carece de todo servicio público, salvo por el suministro de agua para riego que transporta la acequia principal y el transporte en cisterna de agua que emplean para beber y cocinar.

En entrevistas informales se pudo constatar que el segundo sector, hacia el noroeste del sector de La Banda, se comienza a habitar durante la primera mitad del siglo $X^{7}$,

5 Comunicación personal de la Dra. Adriana Callegari.

6 En referencia a La Banda, Zulma Castro comenta que "... cuando llegó mi padre, alrededor de 1920, el pueblo ya estaba..." (entrevista a Zulma Castro; La Banda, Chañarmuyo, 2010); y Silvia Barrionuevo dice, por lo que escuchó de sus abuelos, que "... ya estaba en 1860 ó 1880..." (entrevista a Silvia Barrionuevo; Pueblo Nuevo, Chañarmuyo, 2010).

7 En referencia a Pueblo Nuevo, Zulma Castro dice que la gente se estaba yendo de La Banda porque "... el río estaba rompiendo y llegando..." (entrevista a Zulma Castro; La Banda, Chañarmuyo, 2004). 
en un terreno elevado que lo resguarda de las avenidas del río de manera natural. Este sector se organiza axialmente respecto de la ruta provincial $N^{\circ} 39$, red vial que comunica a Chañarmuyo con los pueblos de Campanas y Pituil (Figura $\mathrm{N}^{\circ}$ 6). La ruta provincial es también la calle principal y los pocos edificios públicos se ubican sobre ella -escuela, jardín, comisaría, centro de salud, museo arqueológico-. Las parcelas están organizadas en trama ortogonal a la calle principal, con una mayor ocupación de viviendas en el entorno inmediato a la misma. A su vez, las viviendas se ubican principalmente hacia el frente de las parcelas. Actualmente, y por la configuración de los cerros y el río, es posible observar que la expansión del pueblo está determinada hacia el norte.

Figura $\mathrm{N}^{\circ} 5$

Esquema actual de Chañarmuyo

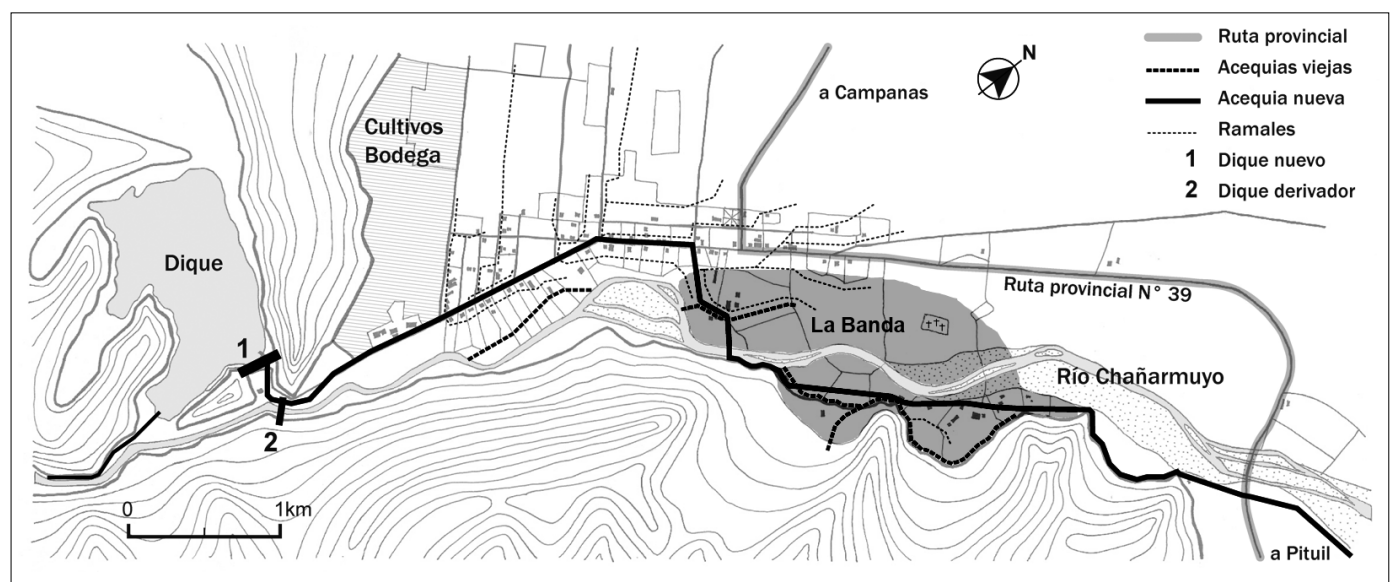

Fuente: Elaboración propia.

Figura $\mathrm{N}^{\circ} 6$

Calle principal en Chañarmuyo

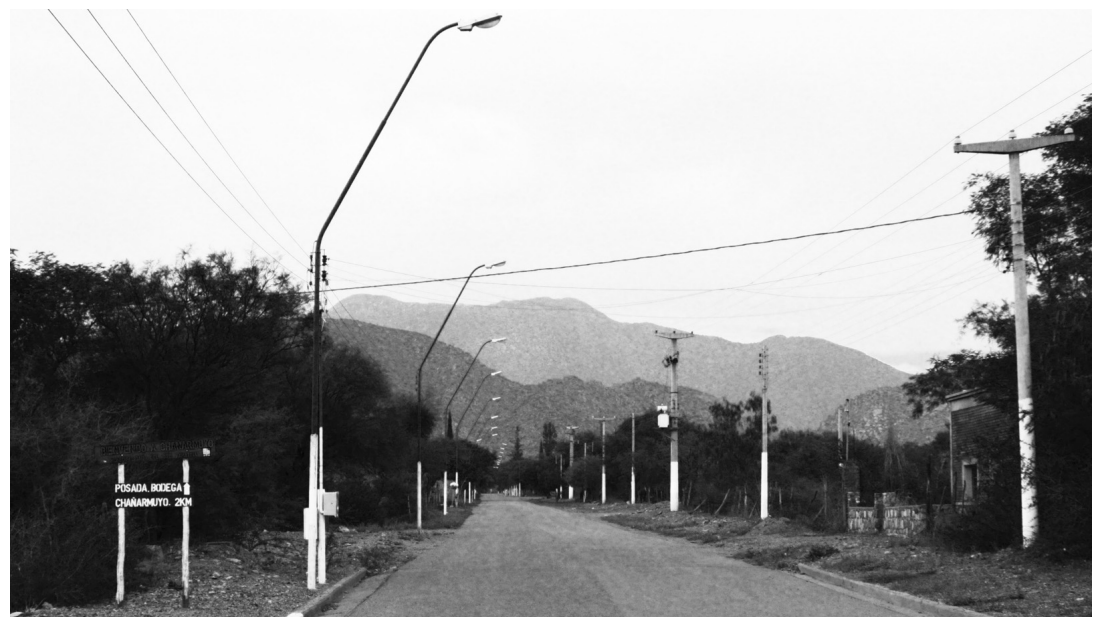

Fuente: Colección personal de los autores. 


\section{Los elementos de ordenamiento: el río, el dique y la acequia}

El río Chañarmuyo tiene sus nacientes en las sierras del Famatina, principal cordón montañoso del centro de la provincia de La Rioja. Está formado por la confluencia de los ríos Chaschuil y Blanco y su cuenca es aproximadamente de $582 \mathrm{~km}^{2}$, con un caudal de $1,525 \mathrm{~m}^{3} / \mathrm{seg}$. Corre en dirección suroestenoreste, culminando con el nombre de río Pituil en las Ilanuras pedemontanas homónimas. Su caudal es estacional, alimentándose de manera esporádica de las Iluvias de septiembre a marzo (AyEE, 1969). Como es característico de los ríos de zonas áridas, tiene avenidas significativas que arrastran gran cantidad de material sólido y que pueden también modificar su recorrido por causa de un proceso erosivo (Salas, 2000).

El dique nuevo de Chañarmuyo (Figura $\mathrm{N}^{\circ}$ 7), como todos los de la provincia, constituye la reserva de agua destinada para riego y para consumo humano ${ }^{8}$. Suplementariamente, y pese a no ser uno de los diques de mayor porte $\left(7,94 \mathrm{hm}^{3}\right)$, también ha pasado a ser un destino regional donde se desarrollan distintas actividades turísticas, principalmente la pesca deportiva. El dique se alimenta del río Chañarmuyo cuya toma se efectúa varios metros río arriba. Su construcción se estudió a principios de la década de 1970 (AyEE, 1969) y las obras finalizaron en 1985 (Bravo Tedín, 1991), reemplazando a un dique derivador previo. Hasta ese momento, las obras existentes que incluían al dique derivador y la acequia principal habían permitido abastecer, con ciertas deficiencias, unas 800 ha entre ambos pueblos (AyEE, 1969).

La acequia principal fue construida y revestida en piedra en la década de 1930 en conjunto con un dique derivador que efec-

\footnotetext{
8 El agua para consumo humano se efectúa a través de red domiciliaria en el sector del Pueblo Nuevo y por cisterna en el sector de La Banda. Este servicio se brinda a través de una empresa privada.
}

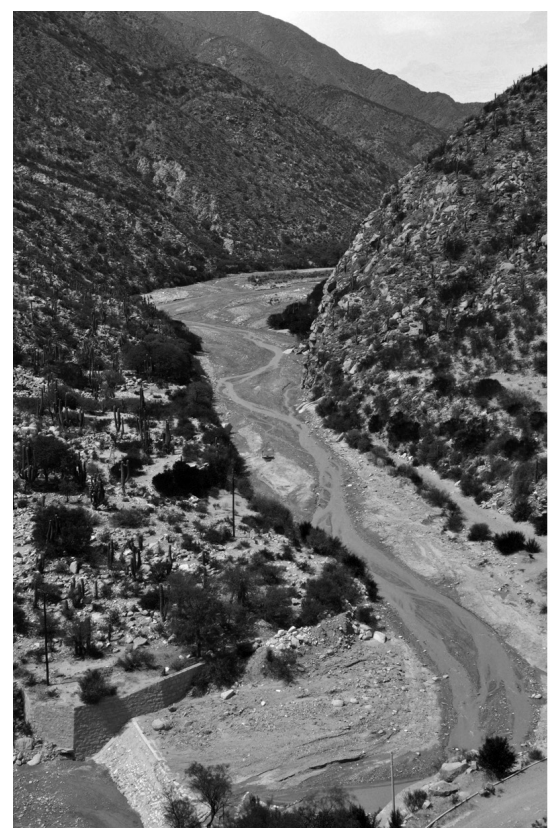

Fuente: Colección personal de los autores.

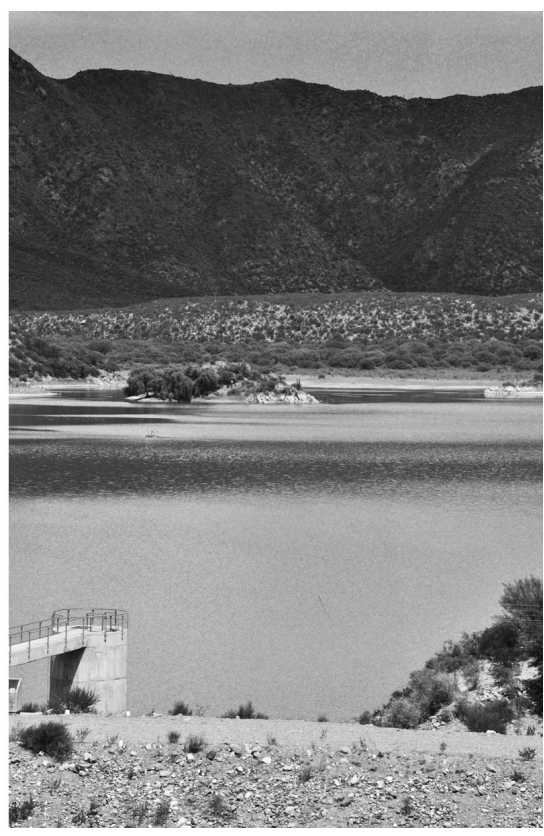


tuaba la toma de agua del río (Bravo Tedín, 1991). La misma transcurre con trayecto sinuoso desde el dique derivador hasta el pueblo de Pituil, al cual también suministra agua de riego; por el Pueblo Nuevo transcurre, en gran parte, paralela y lateralmente a la calle principal (Figura $\mathrm{N}^{\circ}$ 8); luego, a través de un sifón, cruza el río e inmediatamente recorre La Banda (Figura $N^{\circ}$ 9). Se pudo observar que, en este último sector, existen adicionalmente varios tramos de canales que, además de estar vinculados a la acequia principal, aprovechan la escorrentía del agua de lluvia proveniente de los cerros circundantes; estos están cavados directamente sobre el suelo y permanecen en funcionamiento. En ambos sectores se constató que la gran mayoría de las tierras en cultivo se encuentran muy próximas al recorrido de la acequia.

\section{El hábitat rural entre el pequeño y el gran productor}

Como se mencionó, en La Banda permanece una sola familia como pobladores fijos, los Castro, en una de las fincas de mayor extensión de este sector del pueblo; su producción agrícola está destinada en parte al consumo propio y el resto es comprado por acopiadores. Como pequeño productor ${ }^{9}$, se encarga directamente de las tareas rurales vinculadas a su finca y en casos excepcionales recurren a la ayuda remunerada de otros familiares y vecinos. En el sector del Pueblo Nuevo, los cultivos de mayor superficie pertenecen a una empresa con explotaciones agrícolas vitivinícolas, que cuenta además con instalaciones para la producción y fraccionamiento del vino y con servicios destinado al usufructo de las potencialidades turísticas de la región. Además de estos dos actores, que pueden considerarse en situa-

\footnotetext{
9 Definición tomada de Scheinkerman et al. (2007): "se considera pequeño productor a quien dirige una EAP en la que: el productor o socio trabaja directamente en la explotación y no posee trabajadores no familiares remunerados permanentes" (Scheinkerman et al., 2007: 32).
}

Figura $\mathrm{N}^{\circ} 8$

Acequia principal en el Pueblo Nuevo (izquierda) y acequia original en La Banda (derecha)
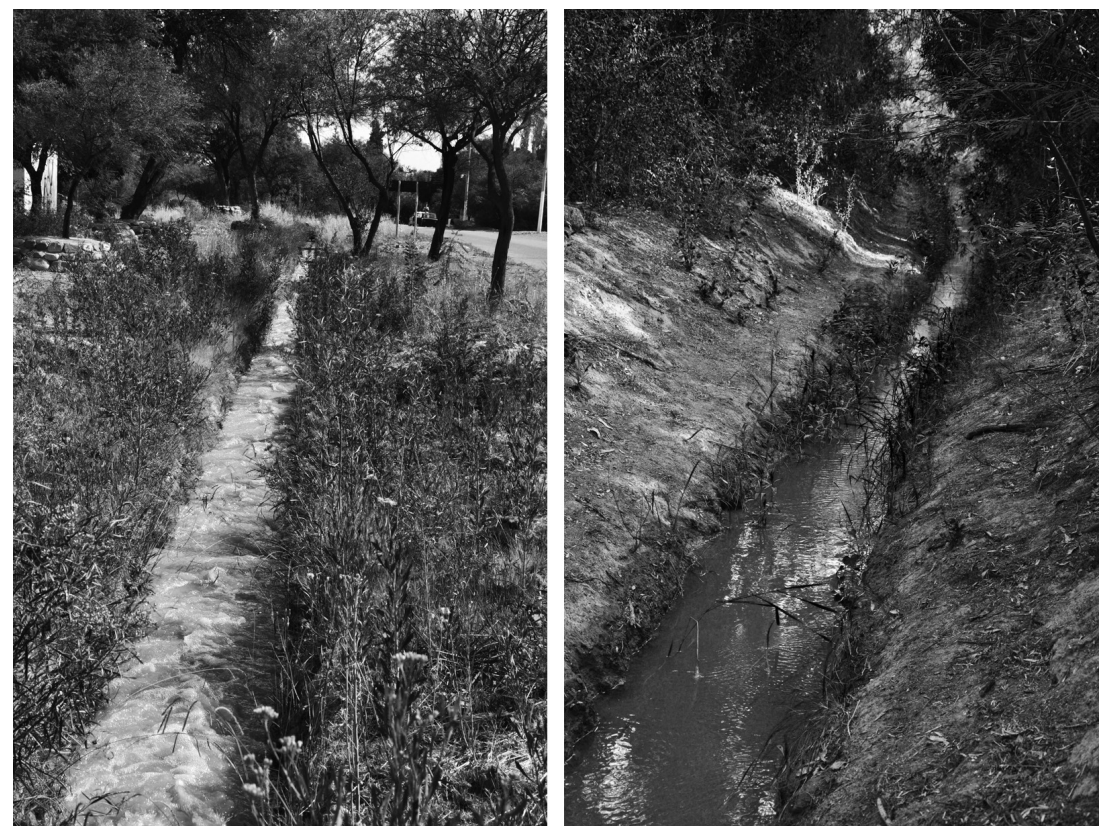

Fuente: Colección personal de los autores. 
ciones de importantes diferencias socioeconómicas y de recursos tecnológicos, se ha identificado -dentro del conjunto de los 70 propietarios de Explotaciones Agropecuarias (EAP) - una significativa proporción de pequeños productores ${ }^{10}$ (Cuadros $\mathrm{N}^{\circ} 1$ y $\mathrm{N}^{\circ} 2$ ).

\footnotetext{
${ }^{10}$ Los pequeños productores para el pueblo de Chañarmuyo suman un total de 67 productores $(95,71 \%)$ con una superficie de EAP de apenas 87,53 ha sobre el total $(19,68 \%)$.
}

Sin embargo, todos están obligados a organizar su producción según la época del año y el correspondiente turno de riego; aspecto donde también se registra una importante diferencia en el acceso al recurso hídrico (Cuadro $N^{\circ} 3$ ). La organización resulta más compleja debido a que en la distribución de la reserva, administrada por los propios regantes constituidos en Consorcio de riego, reúne a 415 productores entre los pueblos de Chañarmuyo y de Pituil (Secretaría del Agua, La Rioja, 2009).

Figura $\mathrm{N}^{\circ} 9$

Acequia principal entre campos de cultivo en La Banda

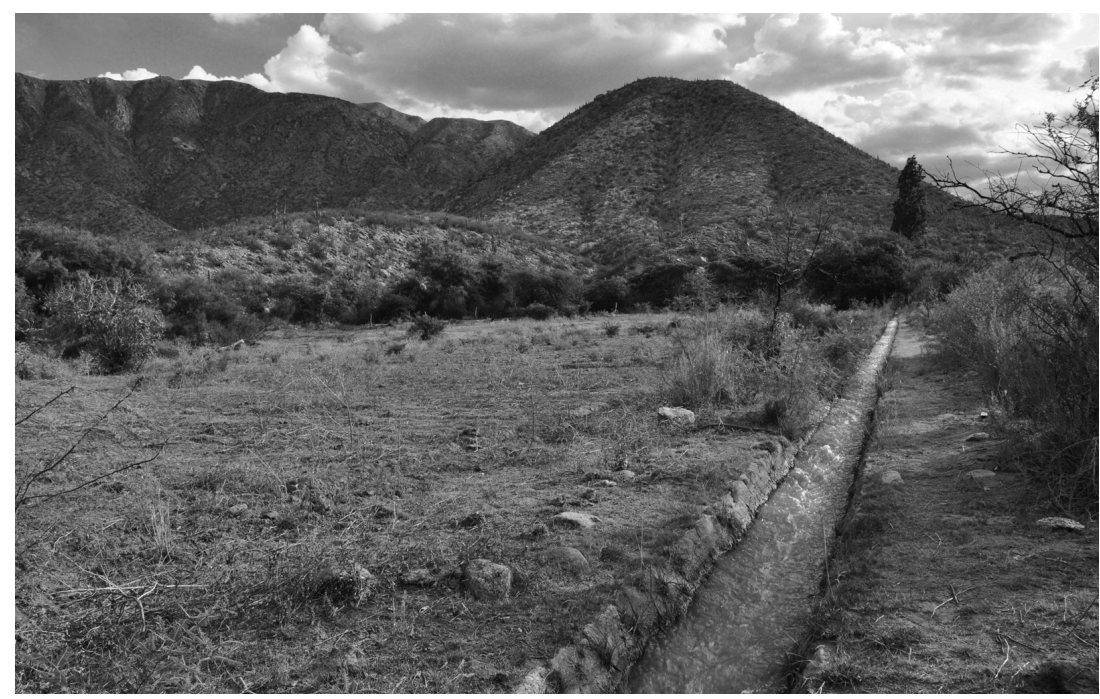

Fuente: Colección personal de los autores.

Cuadro $\mathrm{N}^{\circ} 1$

Chañarmuyo, cantidad de regantes según escala de extensión de sus explotaciones agropecuarias

\begin{tabular}{|l|c|c|c|c|c|c|c|}
\hline & \multicolumn{6}{|c|}{ Escala de extensión de explotaciones agropecuarias (ha) } & \multirow{2}{*}{ Totales } \\
\cline { 2 - 7 } & Hasta 1 & $1-2,5$ & $2,5-5$ & $5-10$ & $10-25$ & Más de 25 & \\
\hline Regantes & 37 & 21 & 6 & 3 & 1 & 2 & 70 \\
Porcentaje (\%) & 52,86 & 30,00 & 8,57 & 4,29 & 1,43 & 2,86 & 100 \\
Superficie (ha) & 16,90 & 31,41 & 19,39 & 19,83 & 11,83 & 345,49 & 444,87 \\
Porcentaje (\%) & 3,80 & 7,06 & 4,36 & 4,46 & 2,66 & 77,66 & 100 \\
\hline
\end{tabular}

Fuente: Elaboración propia en base a datos de la Secretaría del Agua, La Rioja, 2009. 
Cuadro $\mathrm{N}^{\circ} 2$

Chañarmuyo, cantidad de regantes según escala de extensión de las superficies cultivadas en sus explotaciones agropecuarias

\begin{tabular}{|l|l|l|l|l|l|l|l|}
\hline & \multicolumn{5}{|c|}{ Escala de extensión de las superficies cultivadas (ha) } & \multirow{2}{*}{ Totales } \\
\cline { 2 - 7 } & Hasta 1 & $1-2,5$ & $2,5-5$ & $5-10$ & $10-25$ & Más de 25 & \\
\hline Regantes & 58 & 9 & 1 & 1 & 0 & 1 & 70 \\
Porcentaje (\%) & 82,86 & 12,86 & 1,43 & 1,43 & 0,00 & 1,43 & 100 \\
Superficie (ha) & 21,28 & 17,09 & 4,84 & 5,15 & 0,00 & 110,00 & 158,36 \\
Porcentaje (\%) & 13,44 & 10,79 & 3,06 & 3,25 & 0,00 & 69,46 & 100 \\
\hline
\end{tabular}

Fuente: Elaboración propia en base a datos de la Secretaría del Agua, La Rioja, 2009.

Cuadro $\mathrm{N}^{\circ} 3$

Chañarmuyo, cantidad de regantes según escala en horas de riego

\begin{tabular}{|l|c|c|c|c|c|c|c|}
\hline & \multicolumn{6}{|c|}{ Escala en horas de riego (h) } & \multirow{2}{*}{ Totales } \\
\cline { 2 - 7 } & Hasta 1 & $1-5$ & $5-10$ & $10-20$ & $20-50$ & Más de 50 & \\
\hline Regantes & 15 & 45 & 4 & 3 & 2 & 1 & 70 \\
Porcentaje (\%) & 21,43 & 64,29 & 5,71 & 4,29 & 2,86 & 1,43 & 100 \\
Riego (h) & 9,33 & 107,17 & 32,83 & 37,00 & 58,67 & 350,00 & 595,00 \\
Porcentaje (\%) & 1,57 & 18,01 & 5,52 & 6,22 & 9,86 & 58,82 & 100 \\
\hline
\end{tabular}

Fuente: Elaboración propia en base a datos de la Secretaría del Agua, La Rioja, 2009.

\section{La gestión del agua en los valles de La Rioja}

En referencia a la problemática general del recurso agua Coing y Montaño Latts (1988) plantean que "... la escasez de recursos influye sobre el modo de gestión solo en la medida en que los grupos humanos entren en competencia por su utilización y crean relaciones de cooperación, de fuerza, de poder que se traduzcan en modos de gestión" (Coing y Montaño Latts, 1988: 58).

Los primeros antecedentes vinculados a la legislación del agua en la provincia de La Rioja corresponden a una serie de leyes y decretos entre 1866 y 1871 que establecían como principal órgano ejecutor a la Comisión de
Irrigación ${ }^{11}$, siendo el responsable de la administración y mantenimiento del recurso hídrico y restringía al Estado Provincial la función de policía a través de un inspector general.

En un trabajo que aborda las características del desarrollo olivícola en una región específica del norte riojano, Olivera (2001a) describe actores y problemáticas vinculados

\footnotetext{
11 La Comisión de Irrigación estaba formada por cinco integrantes que representaban al Gremio de Agricultores: un presidente, un tesorero, un secretario y dos suplentes. Para integrar el Gremio de Agricultores se debía estar inscripto en el Registro correspondiente al cual se accedía solo si se poseía derecho de agua de ríos, arroyos o manantiales (Archivo Histórico de la Provincia de La Rioja, Ley No 185 de 1869).
} 
con la gestión del servicio del agua durante los últimos doscientos años. En él identifica dos etapas asociadas a la sanción de la Ley Provincial de Irrigación № 550 de 1932.

En la etapa previa a la sanción de la Ley Provincial, la distribución de agua se otorgaba por medio de fracciones horarias fijas (y comerciables) sobre un caudal disponible variable en función de la reserva que se dispusiese: "... desde el siglo XIX, sobre los canales de irrigación de ríos, arroyos y vertientes regía en Arauco -al igual que en otras áreas agrícolas de La Rioja- el sistema de horas de riego, denominado localmente como "turno". Consistía en la rotación de los usuarios para el uso del agua, medido en fracciones (horas y minutos) [...] En cada acequia troncal, arroyo o río había compuertas o tomas desde donde se distribuía el agua a los canales (denominados "la cuadra"). El monto de agua que podía representar, por ejemplo, una hora, variaba según cómo se manejaran las compuertas troncales de los oasis. Para poder asegurar una equitativa distribución del recurso -lo que, obviamente, no implicaba acceso igualitario, sino equivalencia horaria de los litros de agua- existían las comisiones de riego, una por pueblo. Aglutinaban a los vecinos regantes de los diferentes canales [...] Las comisiones de riego tenían competencia sobre tres tipos de "derechos": los turnos de agua para uso agrícola, agua para consumo humano e "industrial", para instalar molinos harineros, ya que estos últimos eran hidráulicos, salvo excepciones" (Olivera, 2001a: 8). El empleo de este sistema de irrigación implicó la introducción de actores específicos como la mencionada Comisión, los Gremios de Agricultores, electores de riego (Bravo Tedín, 1991; Torres, 2006) y aquellos excluidos del derecho de participación por no reunir condiciones mínimas de irrigación (Olivera, 2001a). Posterior a la sanción de la ley, el sistema de distribución se modificó, asociando a cada terreno su cuota de agua e incorporando al Estado (y con ello a sus representantes directos llamados inspectores y tomeros) como actor de peso en este proceso ${ }^{12}$.

\footnotetext{
12 “...Desde la década de 1930 el turno de agua comenzó a aparecer indisolublemente ligado a un terreno en particular y por ende, solo podía ser transferido conjuntamente. Agua y Energía de la
}

Debido a que tanto el mantenimiento de tierras en cultivo como la oportunidad de incorporar nuevas fincas para la producción dependía directamente de la reserva de agua y no de la disponibilidad de parcelas ${ }^{13}$, los conflictos entre campesinos estaban asociados principalmente a la posibilidad de acceso al mismo: "...tanto en la explotación doméstica como en la actividad comercial, el agua aparecía como un factor limitante a tal punto que en las transacciones de propiedades inmobiliarias se indicaba con más detalle la ubicación y el estado de manantiales, aguadas, surgentes y arroyos que los deslindes de dichas propiedades. Su tenencia y usufructo originó más de un pleito entre los pobladores de La Rioja, desde los tiempos de la colonización..." (Mirassou, 2009: 103).

Como constata Olivera (2001a) en entrevistas a pobladores de la región, el amiguismo y el clientelismo jugaron un rol importante en el acceso al recurso durante este período, conformando un complejo funcionamiento de relaciones sociales paralelo y contradictorio con el funcionamiento a las normas legales. Estas prácticas resultaron tan comunes que llegaron a ser reflejadas en el folklore local como se lee en las estrofas de El reparto del Agua del escritor Héctor Gatica (1985).

Actualmente el uso privado de aguas públicas se ha regularizado y es reglamentado por el Decreto Ley $N^{\circ} 4.295$. Esta norma emplea conceptos novedosos como la reserva de aguas por razones ecológicas, sociales o culturales, el estudio previo de la capacidad de explotación de los acuíferos y la planificación de la utilización en función de la demanda presente y proyectada que restringen el otorgamiento indiscriminado de derechos

provincia se erigió en ente mediador de los procesos en marcha, ya que las transacciones entre particulares debían contar con su aprobación. El Estado fiscalizaba y legitimaba esas operaciones, reasignando los turnos de agua cada vez que actualizaba un padrón de regantes..." (Olivera, 2001a)

13 Esto, incluso, cuando la gran mayoría de los propietarios de las fincas no poseyeran el dominio completo, sino una tenencia imperfecta o "título imperfecto" debido a la persistencia del sistema de Mercedes de tierras que rigió incluso hasta mediados de siglo XX (Olivera, 2001b). 
de agua y regula las posibilidades reales de expansión agropecuaria. También establece un orden de prioridades ${ }^{14}$ para el uso y otorgamiento de derechos. A partir de 1997, y en cumplimento con lo establecido en el Art. 102 del Decreto Ley $N^{\circ}$ 4.295, la Ley $N^{\circ} 6.342$ crea y regula el funcionamiento de Consorcio de Usuarios de Agua, una forma descentralizada de gestión a través del cual la comunidad de regantes organizados debe administrar, operar, conservar y mantener su respectivo sistema de riego.

\section{La construcción del paisaje cultural en Chañarmuyo}

Chañarmuyo es, por población y por fisonomía (INDEC, 2001; Roze, 2000; Rolón y Rotondaro, 2009), un asentamiento rural. Las actividades para su subsistencia están íntimamente ligadas al trabajo agrícola y, debido a que sus cultivos requieren irrigación, el agua es fundamental para su desarrollo. Sin embargo, la zona es una región árida donde la disponibilidad del recurso hídrico es escasa. Dadas estas circunstancias, el agua tiene un valor significativo entre sus pobladores que trasciende la mera necesidad de abastecimiento, incidiendo sobre su estructura social y sobre las formas de organización del territorio para alcanzar su aprovechamiento y produciendo una espacialidad rural particular. Tomando en consideración lo propuesto por Natenzon (1989), mencionado al comienzo del trabajo, se infiere que la evolución de la espacialidad de este pueblo riojano transitó por diversas etapas que estuvieron vinculadas a varios procesos afines: los cambios de tecnología en el manejo del agua, las modificaciones en los modos de gestión del recurso hídrico y las transformaciones en las relaciones sociales de los actores afectados.
La evidencia prehispánica mencionada señala que las primeras ocupaciones del territorio próximas al curso del río Chañarmuyo correspondieron a poblaciones originarias. Es probable que en este momento la demanda y el uso de agua del cauce fueran importantes, dado que el asentamiento del sitio La Cuestecilla contó con numerosos campos de cultivos que ocuparon un sector de barreales sobre una extensa planicie. Sin embargo, Callegari sostiene que es posible suponer que no se realizaron mayores intervenciones sobre el río debido a que no se encontraron rastros del uso de diques, sistemas de acequia o similar; aunque existe la posibilidad cierta de que se empleara la simple escorrentía por pendiente entre las parcelas de cultivo debido a las características del terreno ${ }^{15}$.

Las ocupaciones posteriores corresponden al sector de La Banda, conformado por un caserío de viviendas dispersas de muy escasa población. Su emplazamiento a lo largo del cauce del río, principalmente en los sectores a nivel del mismo, así como la existencia de un sistema de precarias acequias cavadas, evidencian el fuerte condicionamiento del medio ambiente, en especial el topográfico y de los primeros esfuerzos técnicos por modificarlo. La presencia de al menos tres tramos de la acequia sin continuidad alguna entre sí, la irregularidad del régimen del río, los riesgos de las fuertes avenidas y la escasez e imprecisión de las precipitaciones son factores que se presentaron contrarios a una acción más coordinada de acceso al recurso hídrico, pudiendo haber condicionado de esta manera una gestión altamente precaria en esta primera instancia. Esta solución técnica inicial posibilitó solo una actividad agrícola de subsistencia o una producción comerciable restringida, directamente dependiente del régimen fluvial y del ciclo de precipitaciones. Además, en la medida que estos factores no cambiaron, continuó limitada toda posibilidad de explorar nuevas parcelas para incrementar la producción agrícola.

\footnotetext{
${ }^{14}$ En el siguiente orden: "Para uso doméstico y municipal y abastecimiento de la población, uso agrícola, uso pecuario, uso industrial, uso medicinal, uso minero, uso energético, uso piscícola y uso recreativo" (Decreto Ley No 4295, artículo № 76).
}

${ }^{15}$ Comunicación personal de la Dra. Adriana Callegari. 
Un primer cambio sustancial se produjo con la construcción del dique derivador, que incluyó además la introducción de un sistema de acequia unificado y más sofisticado, la mejora de la tecnología constructiva empleada y la regularización del suministro y del caudal. Este suceso introdujo fuertes cambios en las formas y posibilidades de una mayor ocupación territorial y posibilitó un aumento de la explotación agrícola. Si bien en las imágenes este beneficio se observa principalmente en el borde norte del río, correspondiente con el sector del Pueblo Nuevo, las fincas de La Banda no dan evidencia de haber disminuido su actividad agropecuaria. Con la posibilidad concreta de incrementar más tierras irrigables, de acceder a áreas mejor protegidas contra la acción del clima y de contar con un suministro permanente de agua, no solo fue posible el incremento de la producción agrícola, sino también el de la población; este aumento es evidente por la densidad de viviendas sobre la calle principal del Pueblo Nuevo.

Además, como consecuencia de la construcción del dique derivador y la acequia, las transformaciones en la tecnología del sistema de riego estuvieron acompañadas por nuevos modos de organización social que marcaron la creación de comisiones de riego y la introducción del Estado en su fiscalización. Estos nuevos factores introducidos transformaron parte del paisaje cultural al aumentar la complejidad social, su nivel de actividad y el grado de conflictividad de la relaciones entre campesinos. De este modo, la diversidad de actores partícipes, tanto aquellos con acceso a derechos como los excluidos, los tradicionales como los nuevos (en relación a la Ley de Irrigación), usuarios como personal de gestión y control, entre otros, se convirtieron en un conjunto de individuos que adquirieron nuevas formas de participación e identidad.

Un siguiente cambio importante ocurrió con las obras del dique actual, calculado para disponer de ingentes volúmenes de agua de riego respecto de los que se obtenía hasta ese momento, que mejoraron y aumentaron sustancialmente la disponibilidad. Por ejemplo, de las imágenes aéreas se observa el desarrollo de cultivos con capacidad de producción industrial asociados a la producción vitivinícola, con la consecuente concen- tración de propiedad y de recursos hídricos como se pueden apreciar en los Cuadros $\mathrm{N}^{\circ}$ $1, N^{\circ} 2$ y $N^{\circ} 3$. También se observa, en el contraste entre imágenes, la presencia de un mayor número de pequeñas parcelas en producción y una mayor consolidación urbana en el Pueblo Nuevo. Sin embargo, en la actualidad se ha alcanzado el límite de suministro produciendo un freno al otorgamiento de nuevos Derechos de Agua ${ }^{16}$. En concordancia con lo que sostienen Oliveira Melo y Fehr (2009) -salvando las diferencias climáticas por un lado y por otro que en Chañarmuyo no se dispone de agua subterránea-, el recurso hídrico es un factor limitante para el desarrollo de la irrigación y de la agricultura.

De este modo, por una parte, la reorientación de las zonas de expansión de los cultivos, el trazado de la acequia principal, retomando en gran parte el trazado de los tramos originales y el definitivo traslado de la población, con modificación en la forma de ocupación y concentración de las viviendas, muestran un replanteo que se formuló sobre la base de condiciones previas. Por otro lado, el contraste producido entre ambos sectores del pueblo sugiere un cambio en la forma de intervenir el medio ambiente natural para ocuparlo: presenta actualmente a La Banda como área casi exclusiva de campos de cultivos y al Pueblo Nuevo como sector de asiento de la población, de nuevas tierras productivas, de la introducción de producción agroindustrial y de la posibilidad de contar con recursos y servicios para las actividades de carácter turístico.

Tomando la idea de que "... la espacialidad y la temporalidad, la geografía y la historia humana, se entrecruzan en un complejo proceso social que crea una secuencia histórica de espacialidades en constante evolución..." (Soja, 1985: 94), se puede considerar que lo ocurrido en este pueblo resulta de un proceso de aprehensión y adaptación al entorno en una primera instancia (La Banda, o incluso remontarnos a La Cuestecilla), para luego pasar a una intervención con transformación del mismo en otra posterior (el Pue-

\footnotetext{
16 Información personal de la Secretaría del Agua, La Rioja, 2010.
} 
blo Nuevo). Desde el punto de vista social, el proceso por medio del cual se complejiza el modo de gestión del recurso hídrico y sus consecuencias sobre las estructuras y prácticas sociales, también son el reflejo de aprehensión y adaptación; los ciclos asociados a los turnos de riego constituyen en sí mismos una imposición en las relaciones sociales que, generada por ellas mismas, le permiten regular sus labores agrícolas y a la vez reafirmar la validez de sus prácticas. Esto es planteado por Coing y Montaño Latts (1988) en referencia a la constitución del modelo de organización: “... el modo de gestión del agua es entonces el resultado de las relaciones sociales que se establecen alrededor de su apropiación y de su uso. Toda evolución de los usos del agua $-y$ de las relaciones entre los usuarios- incide sobre el modo de gestión anterior" (Coing y Montaño Latts, 1988: 59). La proximidad del turno implica que un conjunto de condiciones necesarias, propias del proceso de gestión y de uso del agua, se pongan en funcionamiento para que el riego sea aprovechado; cada actor recrea y reestructura la dinámica de este paisaje cultural ejecutando su rol y desencadenando, consecuentemente, múltiples prácticas sociales (Bourdieu, 1980) vinculadas a la labranza y control del turno de riego; y por su naturaleza cíclica, estas actividades nutren el proceso de creación de la memoria colectiva, necesaria para la reproducción de las prácticas sociales (Ashmore, 2004) que regulan las formas de intervenir el territorio.

\section{Consideraciones finales}

Abordar el tema del paisaje cultural en base a los sistemas de distribución de agua de riego, de sus modos de gestión y de las relaciones sociales que se establecen a partir de ellos puede resultar útil como punto de partida para comprender su construcción en estos pueblos rurales del noreste riojano. Las circunstancias históricas descriptas caracterizan de manera determinante aspectos tales como las posibilidades de localización y traslado de la población o de su estructura agraria, como es el caso de Chañarmuyo.

Aspectos actuales característicos de Chañarmuyo se pudieron observar en el sector norte, con el desarrollo de nuevos y extensos campos de cultivos, principalmente vitivinícolas, donde la concentración de propiedad agrícola y de importantes asignaciones en los derechos de agua en muy pocos actores establece un papel muy importante en la construcción de su paisaje cultural. Por otra parte, se constató la subsistencia de un amplio sector de pequeños productores rurales que, a través de la oportuna reglamentación que vincula derechos de agua y propiedad agrícola y al surgimiento y consolidación del Consorcio de Usuarios de Agua integrados por los propios regantes, les otorga un creciente peso en la organización y control de la distribución del recurso hídrico. Esta problemática es central e históricamente conflictiva en toda la provincia de La Rioja.

También podemos afirmar que, como consecuencia de factores naturales y de las progresivas mejoras implementadas en los sistemas de distribución de agua, el sector originario de La Banda se fue transformando con el tiempo en un área casi exclusiva para cultivos en detrimento de la población estable, y el Pueblo Nuevo como el reciente sector de localización de la población, de la expansión de nuevas fincas y de la aparición de los primeros productores con capacidad de producción industrial del pueblo.

La construcción del paisaje cultural de Chañarmuyo resulta, en gran medida, de la interacción entre ambas áreas del pueblo en su intercambio con la naturaleza y del recuerdo presente en la memoria de sus habitantes, que les permite vincular acontecimientos anteriores con las consecuencias materiales y sociales actuales. El uso del agua, la configuración de su recorrido, la relación con el río, la forma de ocupación del territorio y la construcción de los vínculos sociales, dentro y fuera de las normas legales, son pautas concretas de esta interactividad. Se han modificado sustancialmente, en íntima relación con la implementación y desarrollo de sucesivos sistemas de reserva y distribución del agua para riego y de los modos de su gestión. Es interesante observar que las huellas del conflicto permanente por mediar y acceder a un recurso tan vital como el agua, en estas regiones marginales del territorio para la vida humana, son indicios de la construcción del paisaje cultural. 


\section{Referencias bibliográficas}

ABRAHAM, E. Lucha contra la desertificación en las tierras secas de Argentina. El caso de Mendoza. En: CYTED. El agua en Iberoamérica. De la escasez a la desertificación. Buenos Aires: CYTED, 2002, p. 27-44.

AGUA Y ENERGÍA ELÉCTRICA (AyEE, Empresa del Estado). Estudio de prefactibilidad de aprovechamiento del río Chañarmuyo. Prov. de La Rioja. La Rioja: Secretaría de Energía, Departamento de Estudios y Proyectos, 1969.

ASHMORE, W. Social archaeologies of landscape. In: MESKELL, L. \& PREUCEL, R. (ed.). A companion to social archaeology. Malden: Blackwell, 2004, p. 255-271.

BURMIL, S.; DANIEL, T. \& HETHERINGTON, J. Human values and perceptions of water in arid landscape. Landscape and Urban Planning, 1999, № 44, p. 99-109.

BOURDIEU, P. The Logic of Practice. Stanford: Stanford University Press, 1980.

BRAVO TEDÍN, M. Historia del agua en La Rioja. Córdoba: Proyección Editora, 1991.

CALLEGARI， A.; GONALDI, M.; WISNIESKI, M. y RODRÍGUEZ, M. Paisajes ritualizados. Traza arquitectónica del sitio aguada La Cuestecilla y su área de influencia (Dto. Famatina, La Rioja). En: Mendoza, Actas del XVII Congreso Nacional de Arqueología Argentina, 2010.

CALLEGARI, A.; GONALDI, M. y RAVIÑA, M. Paisaje social y ceremonialismo en La Cuestecilla (Dto. de Famatina, La Rioja). En: CONTRIBUCIÓN ARQUEOLÓGICA $N^{\circ}$ 5. Actas del XIV Congreso Nacional de Arqueología Chilena. Copiapó: Museo Regional de Atacama, 2000, p. 875-893.

CALVO-IGLESIAS, M.; CRECENTEMASEDA, R. \& FRA-PALEO, U. Exploring farmer's knowledge as a source of information on past and presente cultural landscape. A case study from NW Spain. Landscape and Urban Planning, 2006, № 78, p. 334-343.
CASTRO, H. y REBORATTI, C. Revisión del concepto de ruralidad en la Argentina y alternativas posibles para su redefinición. Buenos Aires: Ministerio de Economía y Producción, Secretaría de Agricultura, Ganadería, Pesca y Alimentos, Dirección de Desarrollo Agropecuario PROINDER, 2007. Disponible en Internet: www.proinder.gov.ar

COING, H. y MONTAÑO LATTS, I. La gestión del agua potable en el tercer mundo. Medio Ambiente y Urbanización, 1988, vol. $7, \mathrm{~N}^{\circ} 23$, p. 58-66.

DE LA VEGA DÍAZ, D. Toponimia riojana. La Rioja: Editorial Canguro, 1994.

EBEN SALEH, M. Environmental cognition in the vernacular landscape: assessing the aesthetic quality of Al-Alkhalaf village, Southwestern Saudi Arabia. Building and Environment, 2001, № 36, p. 965-979.

FACULTAD DE AGRONOMÍA DE LA UNIVERSIDAD DE BUENOS AIRES. Informe: Hábitat Rural y pequeña producción en la Argentina. Buenos Aires: Presidencia de la Nación, Convenio SSDV-SDS, 1996.

GATICA, H. El reparto del agua. En: GATICA, H. Cantata riojana. Buenos Aires: Edición del Congreso de la Nación, 1985.

GONZÁLEZ CLAVERÁN, J. La población rural, la vivienda rural y la calidad de vida en los asentamientos rurales de Iberoamérica. En: RED XIV E-CYTED. $1^{\text {a }}$ Memoria Seminario Iberoamericano de Vivienda rural y Calidad de Vida en los Asentamientos Rurales. Morelos: Red XIV E-CYTED, FA UAM Morelos, 1999, p. 51-61.

INGOLD, T. The temporality of the landscape. World archaeology, 1993, № 25, p. 125-174.

INSTITUTO NACIONAL DE ESTADÍSTICA Y CENSOS (INDEC). Censos Nacionales de Población y de Población y Viviendas de 2001. Buenos Aires: INDEC, 2001.

INSTITUTO NACIONAL DE ESTADÍSTICA Y CENSOS (INDEC). Censo Nacional Agropecuario, 2002. Buenos Aires: INDEC, 2002. 
LEÓN, A. y VÁLDES, F. Tecnologías apropiadas actuales para la conservación del agua y del suelo de uso frecuente en Chile. En: CYTED. El agua en Iberoamérica. Uso y gestión del agua en tierras secas. Buenos Aires: CYTED, 2008, p. 31-41.

MIRASSOU, S. La gestión integral de los recursos hídricos: aportes a un desarrollo conceptual para la gobernabilidad del agua. Tesis doctorado. Buenos Aires: FLACSO, Sede Académica, Argentina, 2009.

NATENZON, C. Agua, recurrencia social y organización territorial en Los Llanos de La Rioja. Revista Territorio. Para la producción y crítica en Geografía y Ciencias Sociales, 1989, No 1, p. 1-51.

NÜSSER, M. Understanding cultural landscape transformation: a re-photographic survey in Chitral, eastern Hindukush, Pakistan. Landscape and Urban Planning, 2001, No 57, p. 241-255.

OLIVEIRA MELO, E. y FEHR, M. La evolución del uso del suelo y del agua en la cuenca del arroyo Piçarrão (AraguariMG-Brasil): un estudio de caso. Revista de Geografía Norte Grande, 2009, No 42, p. 59-69.

OLIVERA, G. Olivo, políticas sustitutivas y heterogeneidad agraria (La Rioja 19401970). Mundo Agrario. Centro de Estudios Histórico Rurales, Revista de Estudios Rurales, 2001a, vol. 1, No 2, p. 1-31. Disponible en Internet: http://www.scielo.org.ar/pdf/magr/ v1n2/v1n2a04.pdf

OLIVERA, G. Articulación mercantil y transformaciones sociales agrarias en los Ilanos (La Rioja, 1900-1960). En: BANDIERI, S. Cruzando la Cordillera... La frontera argentino-chilena como espacio social. Neuquén: Centro de Estudios de Historia Regional, 2001b, p. 279-319.

POTTER, R. \& DARMAME, K. Contemporary social variations in household water use, management strategies and awareness under conditions of "water stress": The case of Greater Amman, Jordan. Habitat International, 2010, No 34, p. 115-124.
PROVINCIA DE LA RIOJA. Registro oficial. La Rioja: Provincia de la Rioja, tomo V, 18701871.

ROLÓN, G. y ROTONDARO, R. Persistencia y cambios en la vivienda vernácula. Valles y quebradas riojanos, Argentina. En: Actas del VIII Seminario Iberoamericano de Construcción con Tierra. Tucumán: Universidad Nacional de Tucumán, 2009, p. 490-498.

ROZE, J. Conceptualización de la vivienda rural y la calidad de vida en los asentamientos rurales en Argentina. En: UASLP-CYTED. Memoria 2do Seminario Iberoamericano de Vivienda Rural y Calidad de Vida en los Asentamientos Rurales. San Luis Potosí: UASLP-CYTED, 2000, p. 12-15.

SALAS, J. Hidrología de zonas áridas y semiáridas. Revista Ingeniería del agua, 2000, vol. 7, No 4, p. 409-429.

SALOMÓN, M.; LORA BORRERO, B.; TORRES, L.; TORRES, E.; PASTOR, G.; TORRES GUEVARA, J.; LEÓN, A.; VALDÉS, F. y APÓSTOL, R. V. Componente productivo. 5. Tecnologías de conservación de agua y suelo. En: CYTED. El agua en Iberoamérica. Aportes hacia la integración de distintas disciplinas: glosario técnico del proyecto Indicadores y tecnologías apropiadas de uso sustentable del agua en las tierras secas de Iberoamérica. Mendoza: CYTED, 2008, vol. XIV, p. 277-283.

SOJA, E. The spatiality of social life: towards a transformative retheorization. In: GREGORY, D. \& URRY, J. Social Reations and Spatial Structures. London: Macmillan, 1985, p. 90-127.

SCHEINKERMAN, E.; PILAR FORTI, M. y ROMÁN, M. Los pequeños productores en la República Argentina. Importancia en la producción agropecuaria y en el empleo en base al Censo Nacional Agropecuario 2002. Buenos Aires: Secretaría Agricultura, Ganadería, Pesca y Alimentos, 2007.

TENA NÚÑEZ, R. Vivienda rural, territorio y sustentabilidad. En: RED XIV E-CYTED. $1^{\text {a }}$ Memoria Seminario Iberoamericano de Vivienda rural y Calidad de Vida en los 
Asentamientos Rurales. Morelos: Red XIV E-CYTED, F. A. U. A. M., 1999, p. 134-147.

TORRES, E.; ABRAHAM, E.; MONTAÑA, E.; SALOMÓN, M.; TORRES, L.; URBINA, S. y FUSARI, M. Mendoza y el uso del agua. En: CYTED. El agua en Iberoamérica. Aspectos de la problemática de tierras secas. Buenos Aires: CYTED XVII, 2003, p. 17-34.

TORRES, E.; ABRAHAM, L.; TORRES, L. y RUBIO, C. El poder del agua en las tierras secas de Argentina. En: CYTED. El agua en Iberoamérica. Indicadores y Tecnologías Apropiadas para el Uso del Agua en las Tierras Secas de Iberoamérica. Mendoza: CYTED, 2008, vol. XIII, p. 165-182.

TORRES GUEVARA, J. y CLAROS MAQUERA, D. Saberes, conocimientos y tecnologías tradicionales de uso sustentable del agua en las tierras secas del Perú. En:
CYTED. El agua en Iberoamérica. Uso y gestión del agua en tierras secas. Mendoza: CYTED, 2005, vol. XII, p. 169-187.

TORRES GUEVARA, J. Agua. Formas de uso sostenible. Listado y breve explicación de las tecnologías relevadas con especial referencia a la lucha contra la desertificación. Caso: Perú. En: CYTED. El agua en Iberoamérica. Indicadores y tecnologías apropiadas para el uso del agua en las tierras secas de Iberoamérica. Mendoza: CYTED, 2006, vol. XIII, p. 107-124.

TORRES, N. Organización de usuarios de agua de riego en el departamento Chilecito (La Rioja). En: Mendoza, III Jornadas de Actualización en Riego y Fertirriego, 2006.

UNESCO. Textos básicos de la Convención del Patrimonio Mundial de 1972. Paris: Nuria Sanz París, 2006. 